\title{
Antioxidant Supplements and Oxidative Stress The debate extends to the Middle East
}

"Jumana Saleh, ${ }^{1}$ Marvin Edeas, ${ }^{2}$ Harry Van Goor $^{3}$

$$
\begin{aligned}
& \text { المكملات الغذائية المضادة للأكسدة والإجهاد التأكسدي } \\
& \text { يمتد الجدل إلى الشرق الأوسط }
\end{aligned}
$$

جمانة صالح، مارفين إدياس، هـاري فان غور

$\mathrm{F}$ REE RADICALS ARE ATOMS THAT CONTAIN AN unpaired valence electron that renders them chemically unstable and highly reactive. Free radicals are capable of damaging biological molecules such as nucleic acids, proteins, carbohydrates and lipids leading to cell damage and/or cell death. ${ }^{1}$ These atoms result from normal metabolic processes in the human body as well as from environmental exposure to harmful rays, ozone, cigarette smoking, air pollutants and industrial chemicals. ${ }^{1}$ Antioxidants are compounds that donate electrons to neutralise free radicals and prevent their detrimental effects. Diet is an important source of antioxidants as fruits and vegetables are rich in antioxidants such as polyphenols, vitamin E, vitamin $\mathrm{C}$ and minerals such as selenium. Glutathione is a major endogenous antioxidant which is produced in the intracellular compartment. ${ }^{2}$ The balance between the oxidising effects of free radicals and the reducing power of antioxidants is referred to as "redox homeostasis".

Oxidative stress in humans occurs as a result of the imbalance between free radical production in cells and tissues and the ability of natural antioxidant defences to detoxify them. Exposure to oxidative stress has escalated in modern societies as a result of increased exposure to harmful oxidants in various aspects of life-including diet, industrial pollution, chemicals, medications, smoking, pesticides and many more. Imbalance in the redox state renders the human body more vulnerable to an array of disorders and chronic diseases such as cancer, heart disease, neurological disorders and other diseases linked to aging and disturbed immune function. ${ }^{4-6}$ The International Society of Antioxidants in Nutrition and Health (ISANH) is a non-profit organisation based in Paris, France. ${ }^{7}$ The general aim of this society is to address various factors affecting the redox balance in health and disease, particularly the role of natural and supplemental antioxidants. ISANH conducts regular meetings to encourage communication among researchers, physicians, nutritionists, industry specialists, food technology and strategic marketing managers through global antioxidant networks to enhance knowledge and share ground-breaking discoveries regarding antioxidants, their advantages/disadvantages and provide recommendations to decision-makers and institutions about the latest trends in the field.

Disorders resulting from oxidative stress are prevalent worldwide, including Middle Eastern countries. While the affluent countries in the Middle East have been exposed to the negative effects of industrialisation, their lower income counterparts suffer from a lack of modernisation and healthcare awareness. The ISANH has posed various questions such as 'What are the determinants of oxidative stress related disorders in the Middle East?, 'Are preventive and intervention measures handled effectively?, 'What are the risks of uncontrolled consumption of synthetic antioxidant supplements?' and 'Are natural antioxidant resources appreciated and efficiently utilised?' amongst others. As a result, the ISANH recently established its branch in the Middle East, named the International Society of Antioxidants in Nutrition and Health-Middle East (ISANH-ME), to find answers, share experiences and address matters of regional interest. ${ }^{7}$ ISANH-ME has recently conducted several annual regional meetings in parallel with the European-based version. ISANH-ME meetings started in Dubai, United Arab Emirates (UAE), in 2016, followed by meetings in Beirut, Lebanon, and Amman, Jordan, in 2017 and 2018, respectively. ${ }^{8}$ The fourth ISANHME Congress was held at Sultan Qaboos University, Muscat, Oman, in March 2019.7 A total of 53 prominent speakers from 23 countries all over the world participated in the Congress. A significant number of contributions were made from local researchers and graduate students from different colleges in Oman. The Congress 
sessions were designed to be integrative in nature, spanning basic, translational and clinical applications. Three main themes were addressed: 1) redox in health and nutrition, 2) redox- microbiota links and 3) waste valorisation (i.e. recycling) to retrieve active biomolecules including antioxidants and biofuel components. This editorial aimed to summarise the main aspects discussed during that Congress.

Considering the first theme, participants demonstrated in vivo and in vitro findings emphasising the role of oxidative stress in disease progression in several ailments including cancer, metabolic, cardiovascular, gastrointestinal, reproductive and age-related disorders. Mechanisms of disease progression and potential therapeutic roles of antioxidants were discussed. ${ }^{9}$ Advanced techniques for measuring antioxidants in biological materials were demonstrated. New findings highlighting that the redox status was a significant disease determinant and, in some cases, outperformed other markers of disease severity supporting previous findings., ${ }^{9,10}$

Oxidative stress was linked to hormonal variations in women and was implicated in polycystic ovary syndrome, which is common among Omani women. ${ }^{11,12}$ Two independent studies conducted by researchers in Oman highlighted that homocysteine, a pro-oxidant marker, was a predictive determinant of oxidative stress among Omani women, which could be improved by antioxidant supplementation. ${ }^{10}$

The Middle East is rich in natural resources; antioxidants extracted from natural products and their therapeutic potential, was a predominant aspect of several presentations at this Congress. ${ }^{8}$ Oman has an abundance of original natural resources, particularly with its extended coastal line and diverse marine and terrestrial ecosystems. Speakers from Oman and others presented promising novel findings of products extracted from local plants and marine sources that were proposed to be protective against oxidative stress-related conditions, in particular cancer progression. For example, fucoidans extracted from the seaweed Sargassum ilicifolium exhibited protective effects against gastric cancer in rats. ${ }^{13}$ In another study, bioactive agents extracted from natural and edible wild plants found in Oman were suggested to provide protection against oxidative stress-induced colon cancer through their antioxidant properties. Extracts from the seasonal "desert truffle" were shown to exhibit strong antioxidant and anticancer activities. Also, steroidal glycoalkaloids extracted from local thorn apple or bitter apple (Solanum incanum) plants, which are abundant in Oman, selectively inhibited the proliferation of the worst type of melanoma by inducing oxidative damage and apoptosis of melanoma cancer cell lines..$^{10}$ Moreover, Omani researchers revealed that date extracts exhibited antifibrotic effects that could prevent certain pancreatic pathologies. In another local study, date fruit fibre was proposed as a functional food ingredient for its numerous health benefits. ${ }^{10}$

In spite of promising findings regarding the therapeutic role of antioxidants in fighting against the progression of oxidative stress-related diseases, the consumption of antioxidant supplements, whether natural or synthetic, has become a major area of controversy regarding safe supplementation in terms of dosage and type of antioxidant. This debate was triggered by evidence showing that naturally induced oxidative stress is not always harmful. In fact, oxidants are necessary for several biological processes and mild oxidative stress has regulatory and protective roles against certain diseases especially cancer cell proliferation. ${ }^{14,15}$ Hence antioxidant supplements, in spite of their renowned benefits, may be viewed as a double-edged sword as they could hinder natural oxidant defences targeting cancer cell proliferation. ${ }^{15}$ This long-debated issue was strongly addressed during most recent ISANH-ME Congress. The "key note" lecture, presented by Professor Martin Bergö, a leading researcher in the field from the Karolinska Institute in Sweden, and a member of the Nobel Prize Assembly, showed new evidence suggesting that long-term supplementation with the antioxidants $\mathrm{N}$-acetylcysteine and vitamin $\mathrm{E}$ hampered protective natural oxidant defence mechanisms leading to enhanced lung cancer metastasis. ${ }^{8}$ These findings supported previous findings that showed similar results involving melanoma metastasis. ${ }^{14,16}$ Further evidence was presented by researchers from Lebanon and Brunei showing that the protective anticancer effects of thymoquinone, an active ingredient of black seeds, was attributed to its pro-oxidant effects by inducing apoptosis of cancerous cells via the generation of reactive oxygen species. ${ }^{10}$

The second theme of the congress highlighted major links between antioxidants and the revolutionary topic of "microbiota". ${ }^{0,17}$ The human microbiome is comprised of thousands of various types of bacteria that facilitate digestion, produce vitamins and enhance immunity. ${ }^{18,19}$ Researchers in this field presented findings reflecting that the gut microbiome and overall health were significantly enhanced by antioxidants. For example, antioxidant rich formulated fruits and vegetable supplementation diets caused significant favourable changes on the human microbiome and increased plasma antioxidant levels. Interestingly, lycopene and dark chocolate polyphenols, the molecules conventionally considered to be antioxidants, were shown to exert unexpected properties as powerful prebiotics and were found to be 1,000-folds stronger than fibre. In addition, camel milk, a common beverage in some Middle Eastern regions, was found to contain Bacillus subtilis strains that were proposed to have promising probiotic advantages. ${ }^{10}$ 
The third theme highlighted the importance of recovery of antioxidants from food waste in the Middle East. ${ }^{10}$ The value of food waste stems from the rich content of bioactive molecules, antioxidants and fibres that may be useful in food, pharmaceutical, cosmetic and nutraceutical industries. So far, these substances constitute an underexploited source for the recovery and production of natural compounds. In the Middle East, excessive food waste disposal is reflected in more than one trillion dollars' worth of food wasted each year. ${ }^{10}$ Food waste in the Middle East includes organic wastes generated in hotels, restaurants, canteens, cafeterias, shopping malls and food industries. Professor Richard Maroun from Saint Joseph University in Lebanon, stressed the importance of developing strategic plans to solve this growing issue in the Middle East. ${ }^{10}$ Suggestions were proposed to purify natural antioxidant molecules from food waste and by-products through innovative technologies in order to reintegrate them as valuable additives in several industrial products. For example, extraction of polyphenols from olive leaves and pomegranate peels, that are widely cultivated in the Middle East, appears promising. During harvesting, lost olive leaves represent up to $25 \%$ of the total weight of olives and are generally disposed as waste with no further specific use in spite of their richness in highly bioactive polyphenols. New technologies for maximum extraction of phenolic compounds from olive leaves and pomegranate peels based on infrared irradiation were also shown at the Congress. Researchers from Iran presented findings proposing that the water by-product obtained after hydro-distillation of Rose damascena could be considered as a valuable source of polyphenolic compounds. ${ }^{10}$

A very important aspect of waste valorisation is "bioenergy" which was suggested as a highly promising alternative to fossil-derived energy in a future bio-based economy. Anaerobic digestion is one of the main elements in proposed energy transitions. Industrial by-products from common Middle Eastern waste crops including grapes, olives, pomace, coffee grounds and their conversion into methane was shown to be promising in waste management and bioenergy recovery..$^{10}$ Altogether, these findings aim to establish local and regional initiatives that focus on reliable strategies for better food waste and by-product management and valorisation.

In summary, the themes of the fourth ISANH-ME Congress held in Oman highlighted predictors and mechanisms of disease progression linked to oxidative stress and redox imbalance. A major component was dedicated to antioxidants isolated from natural Middle Eastern products and their promising therapeutic roles. Furthermore, several links between redox balance and the revolutionary science of microbiota were addressed. The effect of antioxidants in promoting a healthy micro- biota was shown in several presentations. On the other hand, the challenging topic of antioxidant overconsumption and their unsupervised usage as dietary supplements was addressed by leading researchers in the field. Strong evidence was presented regarding the dangers of overusing certain antioxidants and their role in promoting cancer progression and metastasis, a topic resonating with the growing interest in cancer research in Oman. The vital issue of food waste recycling in the Middle East was emphasised with recent statistics showing excessive food waste disposal in the region. Strategies of food waste recycling to retrieve essential by-products including antioxidants and biofuels and importance of developing strategic plans to solve this issue were discussed. These included purification of useful waste products and their reintegration as food additives, methods to enhance antioxidant yields and using bioenergy from waste by-products as fossil fuel alternatives.

\section{References}

1. Lobo V, Patil A, Phatak A, Chandra N. Free radicals, antioxidants and functional foods: Impact on human health. Pharmacogn Rev 2010; 4:118-26. https://doi.org/10.4103/0973-7847.70902.

2. Valko M, Leibfritz D, Moncol J, Cronin MT, Mazur M, Telser J. Free radicals and antioxidants in normal physiological functions and human disease. Int J Biochem Cell Biol 2007; 39:44-84. https://doi.org/10.1016/j.biocel.2006.07.001.

3. Young IS, Woodside JV. Antioxidants in health and disease. J Clin Pathol 2001; 54:176-86. https://doi.org/10.1136/jcp.54.3.176.

4. Saha SK, Lee SB, Won J, Choi HY, Kim K, Yang GM, et al. Correlation between oxidative stress, nutrition, and cancer initiation. Int J Mol Sci 2017; 18:E1544. https://doi.org/10.3390/ ijms18071544

5. Vona R, Gambardella L, Cittadini C, Straface E, Pietraforte D. Biomarkers of oxidative stress in metabolic syndrome and associated diseases. Oxid Med Cell Longev 2019; 2019:8267234. https://doi.org/10.1155/2019/8267234.

6. Liguori I, Russo G, Curcio F, Bulli G, Aran L, Della-Morte D, et al. Oxidative stress, aging, and diseases. Clin Interv Aging 2018; 13:757-72. https://doi.org/10.2147/CIA.S158513.

7. International Society of Antioxidants in Nutrition and Health 21st ISANH Redox Congress \& 4th ISANH Middle East World Congress 2019. From: www.isanh.com/?q=node/328 Accessed: Sep 2019.

8. International Society of Antioxidants in Nutrition and Health. From: www.isanh.com/?q=Previous-Conferences Accessed: Sep 2019.

9. Schillern EEM, Pasch A, Feelisch M, Waanders F, Hendriks SH, Mencke R, et al. Serum free thiols in type 2 diabetes mellitus: A prospective study. J Clin Transl Endocrinol 2019; 28:100182. https://doi.org/10.1016/j.jcte.2019.100182

10. Fourth International Society of Antioxidants in Nutrition and Health-Middle East Congress Proceedings. Archives of International Society of Antioxidants. Volume 6, Issue 4, 2019. Pp. 7-42, $44,45,47,48,50-52,54-58$. [Unpublished]

11. Al-Khaduri MM, Al-Farsi YM, Al Najjar TAA, Gowri V, Hospital-based prevalence of polycystic ovarian syndrome among Omani women. Middle East Fertil Soc J 2014; 2:135-8. https:// doi.org/10.1016/j.mefs.2013.06.006. 
12. Sulaiman MA, Al-Farsi YM, Al-Khaduri MM, Saleh J, Waly MI. Polycystic ovarian syndrome is linked to increased oxidative stress in Omani women. Int J Womens Health 2018; 10:763-71. https://doi.org/10.2147/IJWH.S166461.

13. Al-Muqbali MHS, Al-Alawi A, Waly MI, Rahman MS. Anticancer properties of fucoidans extracted from brown seaweed (Sargassum ilicifolium) in a rat model of gastric cancer. Can J Clin Nutr 2019; 7:43-61. https://doi.org/10.14206/canad.j.clin. nutr.2019.02.04.

14. Piskounova E, Agathocleous M, Murphy MM, Hu Z, Huddlestun SE, Zhao Z, et al. Oxidative stress inhibits distant metastasis by human melanoma cells. Nature 2015; 527:186-91. https://doi.org/10.1038/nature15726.

15. Sarangarajan R, Meera S, Rukkumani R, Sankar P, Anuradha G. Antioxidants: Friend or foe? Asian Pac J Trop Med 2017; 10:1111-16. https://doi.org/10.1016/j.apjtm.2017.10.017.
16. Le Gal K, Ibrahim MX, Wiel C, Sayin VI, Akula MK, Karlsson C, et al. Antioxidants can increase melanoma metastasis in mice. Sci Transl Med 2015; 7:308re8. https://doi.org/10.1126/scitra nslmed.aad3740.

17. International Society of Microbiota. About ISM. From: https:// www.microbiota-site.com/about-ism.html Accessed: Sep 2019.

18. Kamada N, Seo SU, Chen GY, Núñez G. Role of the gut microbiota in immunity and inflammatory disease. Nat Rev Immunol 2013; 13:321-35. https://doi.org/10.1038/nri3430.

19. Holzapfel WH, Haberer P, Snel J, Schillinger U, Huis in't Veld JH. Overview of gut flora and probiotics. Int J Food Microbiol 1998; 41:85-101. https://doi.org/10.1016/S0168-1605(98)00044-0. 